\title{
Equilibrium Search with Multiple Attributes and the Impact of Equal Opportunities for Women
}

\section{Melvyn G. Coles}

University of Essex

\section{Marco Francesconi}

University of Essex

\begin{abstract}
This paper considers equilibrium two-sided search with ex ante heterogeneous agents, vectors of attributes, and idiosyncratic match draws. The analysis applies to a large class of models, from the nontransferable utility case to the collective household model with bargaining, for which transferable utility is a special case. The approach is powerful for it identifies a simple algorithm that, in our numerical application, is found to rapidly converge to equilibrium. Our application explores the impact of equal opportunities for women in the labor market on female match incentives and the timing of marriage.
\end{abstract}

\section{Introduction}

This paper considers equilibrium two-sided search in which ex ante heterogeneous individuals have vectors of attributes. In the existing search literature the restriction to a single attribute is almost universal for the

We thank the editor (James Heckman) and five anonymous referees for their very useful comments and suggestions. We are also grateful to Carlos Carrillo-Tudela, Raquel Fernandez, John Knowles, Costas Meghir, José-Víctor Ríos-Rull, and Kjetil Storesletten. The paper has also benefited from the discussions with participants at the 2013 Move Conference in Barcelona, the 2013 Family Economics Conference in Girona, and seminars at Aarhus, Essex, National Research University Higher School of Economics-Moscow, and Oxford. Data are provided as supplementary material online.

Electronically published January 4, 2019

[ Journal of Political Economy, 2019, vol. 127, no. 1]

(c) 2019 by The University of Chicago. All rights reserved. 0022-3808/2019/12701-0003\$10.00 
aggregation problem is severe: ex ante heterogeneous singles use different match strategies and equilibrium requires that each individual's strategy must be a best response to the aggregated match strategies of the opposite sex. We provide a complete characterization of equilibrium and an existence proof when agents have vectors of attributes. Although the paper focuses on the nontransferable utility case (in the sense of Burdett and Coles [1997]), the arguments apply equally to the collective household case (e.g., Browning and Chiappori 1998) for which transferable utility is a special case and also allows idiosyncratic match draws as first considered in Burdett and Wright (1998). The approach is powerful for it identifies a simple algorithm that, in the numerical application, is found to rapidly converge to equilibrium. We use the framework to consider the impact of equal labor market opportunities for women on female education choice, labor market participation rates, partner choice, and welfare.

Following seminal work by Becker $(1973,1974)$, it is well known that partnerships between men and women are positively sorted along many dimensions such as age, income, education, ethnic origin, health, height, and psychometric scores (e.g., Fisman et al. 2006; Hitsch, Hortaçsu, and Ariely 2010; Belot and Francesconi 2013). With frictionless matching, the existence of stable-match allocations with multiple attributes has long been established (see Browning, Chiappori, and Weiss [2014] for a useful survey). Given a restriction to finite types and transferable utility, Choo and Siow (2006) show how observed marriage patterns can be used to exactly identify the gains to marriage, while Galichon and Salanié (2010) and Dupuy and Galichon (2014) extend that approach to allow a continuum of types. ${ }^{1}$ Here instead we consider equilibrium matching with frictions in which, even with modern-day internet dating sites, it takes time for singles to find mutually desired life partners. An important difference is that when rejecting a potential match, the agent's outside option here is to continue to search for a preferred partner (rather than match immediately with someone else or remain permanently unmatched). The resulting framework simultaneously addresses sorting issues (who marries whom) along with the timing of marriage (who marries when).

There is a large literature on equilibrium search with ex ante heterogeneous agents. ${ }^{2}$ By extending that framework to multiple female at-

\footnotetext{
${ }^{1}$ See also Galichon, Kominers, and Weber (2019) for a more general analysis. Chiappori, Oreffice, and Quintana-Domeque (2012) construct a model with multiple characteristics, which, however, reduces to matching along a one-dimensional index.

${ }^{2}$ The marriage approach typically assumes nontransferable utility. See, e.g., Lu and McAfee (1996), Burdett and Coles (1997, 1999), Eeckhout (1999), Bloch and Ryder (2000), Chade (2001), Chade and Ventura (2002), Smith (2006), Gautier, Svarer, and Teulings (2010), Coles and Francesconi (2011), and Díaz-Giménez and Giolito (2013). The labor market context instead assumes that utility is transferable with Nash bargaining over the wage paid; see, e.g., Shimer and Smith (2000). Recent work with multiple attributes includes Goussé, Jacquemet, and Robin (2017) and Lindenlaub and Postel-Vinay (2017).
} 
tributes, we analyze how the arrival of equal opportunities radically transformed female match incentives in the marriage market. Our focus is motivated by figures 1 and 2, which describe the large change in female economic outcomes in the United States following the 1950s. Figure 1 shows the employment rates of women aged 25-34. Single (never-married) women in this age group have always had relatively high labor market participation rates (around 80 percent since 1940). But for this same age group, the labor market participation rates of women with children dramatically increased following the early 1950s. With household production increasingly sustained by new labor-saving appliances, children safely at school, and a doubling of real wages from the mid-1930s to 1960, mothers had an ever-increasing incentive to switch more of their time to the booming labor market (Greenwood, Seshadri, and Vandenbroucke 2005; Greenwood, Seshadri, and Yorukoglu 2005). But prior to the 1964 Civil Rights Act, "marriage bars" were commonly used in professions such as doctors, lawyers, teachers, and clerks to restrict the employment prospects of married women (see Kessler-Harris 1982, 2001; Goldin 1990, 1991). These marriage bars had real bite: of those married women who were labor market participants in 1920, only 10 percent were employed as teachers or clerical workers. By 1970 that statistic had risen to 40 percent (Goldin 1991).

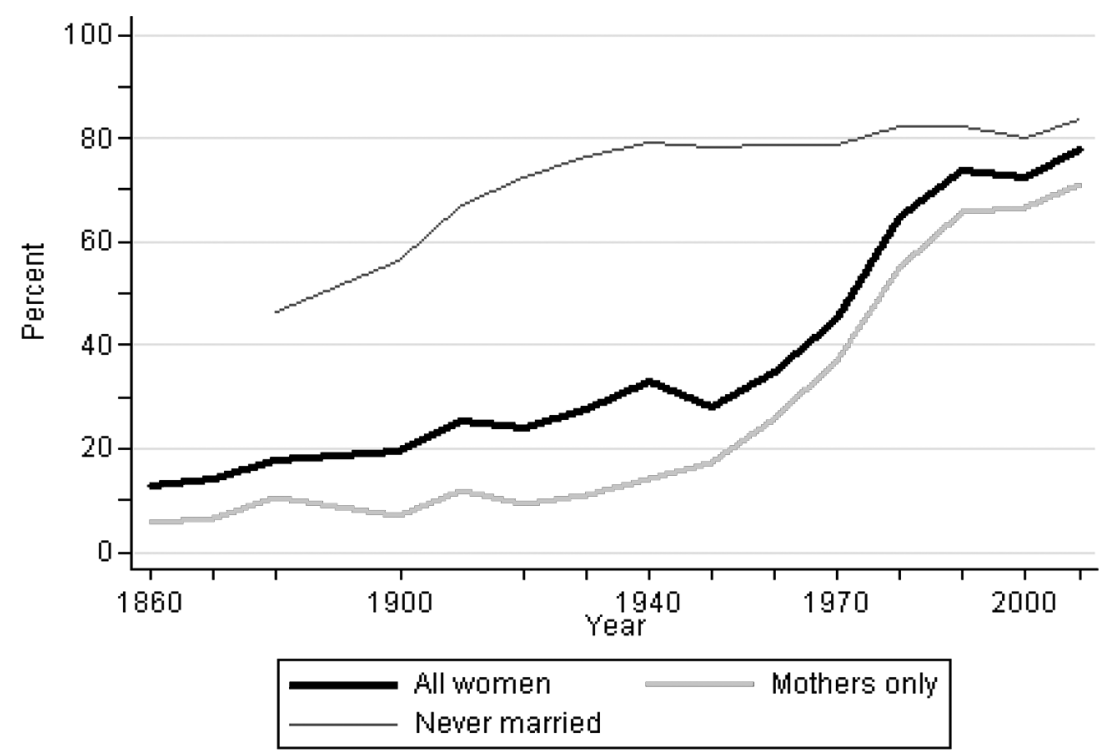

FIG. 1.-Female employment rate, women aged 25-34. Sources: IPUMS census 18602000, 2009 ACS sample. See the appendix for a description of the data and variables used. Color version available as an online enhancement. 


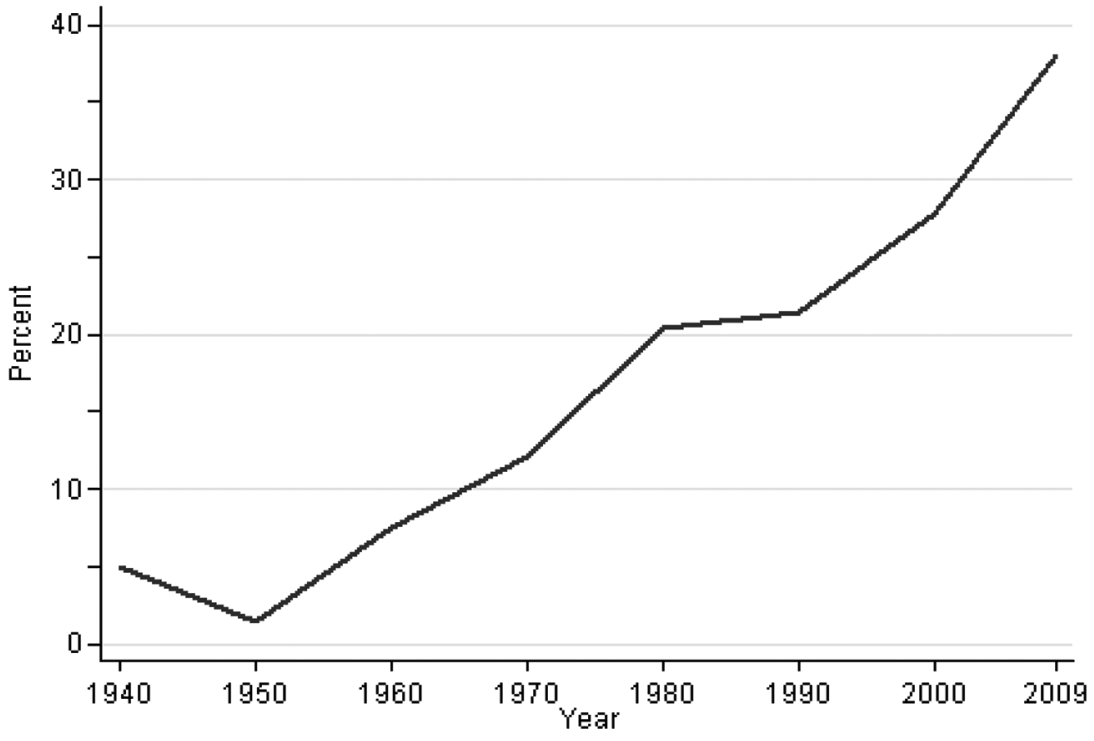

FIG. 2.-Fraction of female college graduates, women aged 25-34. See sources and note to figure 1. Color version available as an online enhancement.

Improved labor market opportunities for women increase the female return to college education. Rather than participating in the labor market for just a few years while single and childless, young women might instead anticipate a lifelong return to a professional qualification. Over the period 1940-2009 and for the same age group 25-34, figure 2 reports the fraction of these women with a college education and so captures the average education choice of women in the 15-24 age group made in the previous decade. Assuming rational expectations, figure 1 then describes female expectations of future labor market participation rates when a mother. Beginning in the 1950s, figures 1 and 2 demonstrate the decades-long, coincident increases in the labor market participation rates of mothers and the college attendance rates of (young) females.

There is a large literature detailing how female economic opportunities improved following the 1950s. For example, Greenwood et al. (2016) argue that changes in home production technologies (the "engines of liberation") were the primary factor for increased female labor market participation. Albanesi and Olivetti (2016) describe how the development of infant formula and improved medication freed the nursing mother from the home. ${ }^{3}$ In contrast, using occupational choice data, Hsieh et al. (2018)

\footnotetext{
${ }^{3}$ A number of studies emphasize a positive impact of wartime work on women's subsequent employment and economic condition. See, among others, Acemoglu, Autor, and Lyle (2004), Goldin and Olivetti (2013), and Doepke, Hazan, and Maoz (2015).
} 
argue that college discrimination was the major factor in distorting labor market outcomes. The 1964 Civil Rights Act, which outlawed restrictive employment practices against women, also played an important role. We do not consider here the relative impact played by each of these factors in improving the female economic condition. ${ }^{4}$ Rather, the focus of our application is to understand how a major advancement in female labor market opportunities affects marital incentives.

Because female education rates have changed so radically since the 1950 s, the numerical application extends the matching framework to allow ex ante investment by agents - that women may invest in a college education (also see Greenwood et al. 2016; Goussé et al. 2017). Because the return to female education choice depends on the (endogenous) proposal strategies of men, however, the investment problem may not be well behaved. Indeed Burdett and Coles (2001) analyze a search equilibrium in which agents vary by a single attribute and find that the marginal return to investment is neither continuous, decreasing, nor bounded. Nor need it be the case, say, that higher-ability women have a greater return to education. To obtain results, the application restricts attention to a binary education choice and must check numerically that private investments are optimal.

The numerical application supposes that women have two attributes, "ability" and "charm," where ability describes earnings capabilities in the labor market while charm is assumed a nonproductive asset in the labor market but is valuable in the marriage market. ${ }^{5}$ The key presumption is that the arrival of equal opportunities for women much increased the (labor market) return to female ability. Because charm and ability provide very different matching incentives for single women, the arrival of equal opportunities for women fundamentally changed female match outcomes, marital sorting, and the timing of life partnerships. For example, we find that a "family tax," as implied by standard OECD equivalence scales, explains why high-ability (highly paid, college-educated) women are relatively slow to match. In contrast, more charming women tend to match relatively quickly, for charm in the model does not pay the bills while single and the charming single woman can monetize the value of her charms only by matching with a desirable life partner.

\footnotetext{
4 The change in public policies and attitudes to the employment of married women with children had a tremendous impact on female behavior, occupations, and earnings (Beller 1982; Harrison 1988; Rosen 2000). Fernandez, Fogli, and Olivetti (2004) find evidence that attitudes of men brought up in families in which the mother worked played a significant role in the increase in female labor force participation over time. See also Costa (2000) and Goldin (2006).

5 Of course male preferences over female partners may depend on many attributes, e.g., (potential) inheritance (Stone 1977), physical beauty (Cole, Mailath, and Postlewaite 1992), pizzazz (Burdett and Coles 1997), nurturing skills (Goldin and Katz 2002), or simply home productivity.
} 
The next section describes the equilibrium marriage model of twosided search with vectors of attributes, idiosyncratic match draws, and general payoff functions for two cases: (i) nontransferable utility and (ii) the collective household model. Section III describes the application of the model to the arrival of equal opportunities for women, extended to allow endogenous investment. Section IV presents conclusions.

\section{The Model}

We establish the key arguments assuming nontransferable utility (in the search sense; see Burdett and Coles 1997). The second part then extends to the collective households case (Chiappori 1992).

\section{A. Nontransferable Utility}

We consider a continuous-time, infinite horizon family formation model with frictions and nontransferable utility (NTU). Only steady-state equilibria are considered. There are two sexes, male and female (indexed by $s=m$, $f$, respectively), and a continuum of agents of both sexes. All partnerships involve one man and one woman, and there is an equal measure of unpartnered men and women in the singles market. Search is random, and $\lambda>0$ denotes the rate at which any single meets a potential partner of the opposite sex. For simplicity all agents are infinitely lived and discount the future at rate $r>0$, and partnerships last forever (i.e., there is no divorce).

Each male is described by a vector of characteristics $\underline{x}_{m} \in \Omega_{m}$ and each female by vector $\underline{x}_{f} \in \Omega_{f}$. Should a male $\underline{x}_{m}$ match with a female $\underline{x}_{f}$, the male obtains payoff $U_{m}\left(\underline{x}_{m}, \underline{x}_{f}\right)+\theta^{m} / r$, while the female enjoys payoff $U_{f}\left(\underline{x}_{m}, \underline{x}_{f}\right)+\theta^{f} / r$. The partners' attribute-dependent payoffs $U_{m}(\cdot)$ and $U_{f}(\cdot)$ are assumed bounded for all $\left(\underline{x}_{m}, \underline{x}_{f}\right) \in\left(\Omega_{m} \times \Omega_{f}\right)$. The $\theta^{m}, \theta^{f}$ terms describe idiosyncratic "love" draws, considered as independent random draws from exogenous cumulative distribution function $H(\cdot)$. We do not rule out mass points in $H$ and so can allow that $H(\cdot)$ is degenerate (i.e., no love draws). What is essential is that the surplus function $S(\tilde{\theta})=\int_{\tilde{\theta}}^{\infty}[1-H(\theta)] d \theta$ exists, which is a positive, continuous, decreasing function with $\lim _{\tilde{\theta} \rightarrow \infty} S(\tilde{\theta})=0$. The flow payoff while single is $u_{m}\left(\underline{x}_{m}\right) \geq 0$ for males and $u_{f}\left(\underline{x}_{f}\right) \geq 0$ for females, which are also bounded functions for all $\left(\underline{x}_{m}, \underline{x}_{f}\right) \in\left(\Omega_{m} \times \Omega_{f}\right)$.

Let $G_{m}\left(\underline{x}_{m}\right)$ describe the distribution of male attributes $\underline{x}_{m}$ across single men and $G_{f}\left(\underline{x}_{f}\right)$ the distribution of female attributes $\underline{x}_{f}$. Random search implies that should single male $\underline{x}_{m}$ meet a single woman, her attributes $\underline{x}_{f}$ are considered a random draw from $G_{f}(\cdot)$. Similarly from her perspective, his attributes $\underline{x}_{m}$ are a random draw from $G_{m}(\cdot)$. Given a contact, each observes the other's attributes and draws independent love values 
$\left(\theta^{m}, \theta^{f}\right)$. A match is formed only if both agree to it; otherwise they separate and continue to search.

If two singles agree to form a match, they permanently exit the singles market and have two children, a son who inherits his father's characteristics $\underline{x}_{m}$ and a daughter who inherits her mother's characteristics $\underline{x}_{f}$. As we consider only steady states, there is no further loss in generality by assuming each child instantaneously grows up and immediately enters the singles market. Burdett and Coles (1999) refer to this as the "clones assumption." The clones assumption is convenient for it usefully abstracts from intercohort competition for partners: the decision to form a match and exit the pool of singles does not affect the match opportunities of the remaining singles. ${ }^{7}$ The approach is relevant for the birth cohort distribution is then endogenously determined. For example, types who never marry, and so do not have children, are absent from the birth cohort. Conversely, those who match quickly are overrepresented in the birth cohort (and in the general population).

Strategies and values.-Let $V^{m}\left(\underline{x}_{m}\right)$ denote the expected discounted lifetime payoff of a single male with attributes $\underline{x}_{m}$ using an optimal match strategy. Let $V^{f}\left(\underline{x}_{f}\right)$ denote the corresponding value of a single female with characteristics $\underline{x}_{f}$. With NTU and given contact with female $\underline{x}_{f}$, a male $\underline{x}_{m}$ will propose a partnership if and only if his match payoff $U_{m}\left(\underline{x}_{m}, \underline{x}_{f}\right)+$ $\theta^{m} / r$ exceeds the value of remaining single, $V^{m}\left(\underline{x}_{m}\right)$. His optimal proposal strategy thus has the reservation love property: the single male will propose if and only if $\theta^{m} \geq \tilde{\theta}^{m}$, where

$$
\tilde{\theta}^{m}=r\left[V^{m}\left(\underline{x}_{m}\right)-U_{m}\left(\underline{x}_{m}, \underline{x}_{f}\right)\right],
$$

and $\tilde{\theta}^{m}=\tilde{\theta}^{m}\left(\underline{x}_{f} \mid \underline{x}_{m}\right)$ is type specific. We define the male proposal propensity as

$$
P^{m}\left(\underline{x}_{f} \mid \underline{x}_{m}\right)=1-H\left(\tilde{\theta}^{m}\right),
$$

which, given a contact, is the probability that male $\underline{x}_{m}$ will propose to female $\underline{x}_{f}$.

By symmetry, given contact with male $\underline{x}_{m}$, single female $\underline{x}_{f}$ has reservation love value $\tilde{\theta}^{f}\left(\underline{x}_{m} \mid \underline{x}_{f}\right)$ given by

$$
\tilde{\theta}^{f}=r\left[V^{f}\left(\underline{x}_{f}\right)-U_{f}\left(\underline{x}_{f}, \underline{x}_{m}\right)\right],
$$

and the female proposal propensity is

\footnotetext{
${ }^{6}$ An alternative is to assume that each child's attribute is a mix of his or her parents' characteristics plus a random element. Similarly, one might wish to endogenize the fertility choice. Both extensions are potentially important research projects but go beyond the scope of the current paper.

${ }^{7}$ This assumption parallels that of the frictionless approach in which the set of unmatched agents is exogenous.
} 
OOO

$$
P^{f}\left(\underline{x}_{m} \mid \underline{x}_{f}\right)=1-H\left(\tilde{\theta}^{f}\right) .
$$

Given proposal propensities (1) and (2), we now determine values $V^{m}\left(\underline{x}_{m}\right)$ and $V^{f}\left(\underline{x}_{f}\right)$.

Recall that a single male $\underline{x}_{m} \in \Omega_{m}$ meets a potential female partner at rate $\lambda$ whose traits $\underline{x}_{f}$ are considered a random draw from $G_{f}(\cdot)$. Standard arguments imply $V^{m}\left(\underline{x}_{m}\right)$ is identified by the Bellman equation:

$$
r V^{m}\left(\underline{x}_{m}\right)=u_{m}\left(\underline{x}_{m}\right)+\lambda \int_{\underline{x}_{f} \in \Omega_{f}} \Pi^{m}\left(\underline{x}_{m}, \underline{x}_{f}\right) P^{f}\left(\underline{x}_{m} \mid \underline{x}_{f}\right) d G_{f}\left(\underline{x}_{f}\right),
$$

where

$$
\Pi^{m}\left(\underline{x}_{m}, \underline{x}_{f}\right)=\int_{-\infty}^{\infty} \max \left[U_{m}\left(\underline{x}_{m}, \underline{x}_{f}\right)+\theta^{m} / r-V^{m}\left(\underline{x}_{m}\right), 0\right] d H\left(\theta^{m}\right) .
$$

In words, random matching implies that $\lambda P^{f}\left(\underline{x}_{m} \mid \underline{x}_{f}\right) d G_{f}\left(\underline{x}_{f}\right)$ is the rate at which male $\underline{x}_{m}$ contacts a single female of type $\underline{x}_{f} \in \Omega_{f}$ who is willing to match with him. Given such a contact, he then enjoys expected surplus $\Pi^{m}\left(\underline{x}_{m}, \underline{x}_{f}\right)$ depending on whether his realized match payoff $U_{m}(\cdot)+\theta^{m} / r$ exceeds $V^{m}(\cdot)$. Integrating (3) by parts implies $\Pi^{m}\left(\underline{x}_{m}, \underline{x}_{f}\right)=S\left(\tilde{\theta}^{m}\right) / r$, where $\tilde{\theta}^{m}$ is his reservation love value and $S(\cdot)$ is the surplus function. Hence $V^{m}\left(\underline{x}_{m}\right)$ is the solution to the implicit function

$$
\begin{aligned}
r V^{m}= & u_{m}\left(\underline{x}_{m}\right)+\frac{\lambda}{r} \int_{\underline{x}_{f} \in \Omega_{f}} S\left(r\left[V^{m}-U_{m}\left(\underline{x}_{m}, \underline{x}_{f}\right)\right]\right) \\
& \times P^{f}\left(\underline{x}_{m} \mid \underline{x}_{f}\right) d G_{f}\left(\underline{x}_{f}\right) .
\end{aligned}
$$

Given $\underline{x}_{m}$ and female proposal strategies $P^{f}(\cdot) \in[0,1]$, (4) determines $V^{m}=V^{m}\left(\underline{x}_{m}\right)$. The properties of the surplus function $S(\cdot)$ imply that the right-hand side of (4) is a positive, continuous, decreasing function of $V^{m}$ that limits to $u_{m}\left(\underline{x}_{m}\right)$ as $V^{m} \rightarrow \infty$. It follows that $V^{m}\left(\underline{x}_{m}\right)$ exists, is unique, and implies $V^{m}\left(\underline{x}_{m}\right) \geq u_{m}\left(\underline{x}_{m}\right) / r$. Note this argument does not imply $V^{m}\left(\underline{x}_{m}\right)$ is continuous for $P^{f}(\cdot)$ need not be continuous in $\underline{x}_{m}$; see, for example, the equilibrium class structure in Burdett and Coles (1997). Fortunately, continuity is not necessary for the existence proof.

By symmetry, $V^{f}=V^{f}\left(\underline{x}_{f}\right)$ is given by

$$
\begin{aligned}
r V^{f}= & u_{f}\left(\underline{x}_{f}\right)+\frac{\lambda}{r} \int_{\underline{x}_{m} \in \Omega_{m}} S\left(r\left[V^{f}-U_{f}\left(\underline{x}_{f}, \underline{x}_{m}\right)\right]\right) \\
& \times P^{m}\left(\underline{x}_{f} \mid \underline{x}_{m}\right) d G_{m}\left(\underline{x}_{m}\right) .
\end{aligned}
$$

Equations (4) and (5) thus uniquely determine $V^{m}\left(\underline{x}_{m}\right)$ and $V^{f}\left(\underline{x}_{f}\right)$ for all $\left(\underline{x}_{m}, \underline{x}_{f}\right) \in\left(\Omega_{m} \times \Omega_{f}\right)$ given the proposal propensities of the opposite sex. Of course equilibrium will require the proposal propensities to be consistent with these values. 
Before defining and establishing the existence of equilibrium, it is useful first to detail how changes in proposal strategies affect agent values. Specifically, consider a woman $\underline{x}_{f}$ and two different proposal strategies by men, $P_{1}^{m}(\cdot)$ and $P_{0}^{m}(\cdot)$. Let $V_{1}^{f}\left(\underline{x}_{f}\right)$ and $V_{0}^{f}\left(\underline{x}_{f}\right)$ denote the solutions to (5) with $P^{m}$ equal to $P_{1}^{m}$ and $P_{0}^{m}$, respectively.

Lemma 1. If $P_{1}^{m}\left(\underline{x}_{f} \mid \underline{x}_{m}\right) \geq P_{0}^{m}\left(\underline{x}_{f} \mid \underline{x}_{m}\right)$ for all $\underline{x}_{m} \in \Omega_{m}$, then $V_{1}^{f}\left(\underline{x}_{f}\right) \geq$ $V_{0}^{f}\left(\underline{x}_{f}\right)$.

Lemma 1 simply says that a woman $\underline{x}_{f}$ is better off when all men are more likely to propose to her. The result follows immediately from (5): for any given $V^{f}$ and noting that the surplus function is positive, the right-hand side of this equation is increasing in $P^{m}$. Thus $V^{f}$ solving (5) must increase with an increase in $P^{m}$.

We can now identify an upper bound on values. Lemma 1 implies that the ideal situation for each male $\underline{x}_{m}$ is that all women propose with probability one; that is, $P^{f}=1$ for all $\underline{x}_{f} \in \Omega_{f}$. Now consider his ideal match $\underline{x}_{f}^{*}$ defined as

$$
\underline{x}_{f}^{*}\left(\underline{x}_{m}\right)=\arg \max _{\underline{x}_{f} \in \Omega_{f}} U_{m}\left(\underline{x}_{m}, \underline{x}_{f}\right) .
$$

It follows that $V^{m}\left(\underline{x}_{m}\right) \leq \bar{V}^{m}\left(\underline{x}_{m}\right)$, where

$$
r \bar{V}^{m}=u_{m}\left(\underline{x}_{m}\right)+\frac{\lambda}{r} S\left(r\left[\bar{V}^{m}-U_{m}\left(\underline{x}_{m}, \underline{x}_{f}^{*}\right)\right]\right),
$$

for $\bar{V}^{m}$ describes the value of being single in a market where all women propose and every woman is also his ideal match. The assumptions on $S(\cdot)$ guarantee that $\bar{V}^{m}$ defined by (6) exists and $\bar{V}^{m} \geq u_{m}\left(\underline{x}_{m}\right) / r$. We have thus established the following result.

Lemma 2. For any male $\underline{x}_{m} \in \Omega_{m}$ and female proposal strategies $P^{f}(\cdot) \in[0,1]$, the solution for $V^{m}\left(\underline{x}_{m}\right)$ exists, is unique, and is bounded with

$$
V^{m}\left(\underline{x}_{m}\right) \in\left[\frac{u_{m}\left(\underline{x}_{m}\right)}{r}, \bar{V}^{m}\left(\underline{x}_{m}\right)\right] .
$$

Armed with lemmas 1 and 2, we are now in a position to define and establish the existence of an equilibrium. The definition of a matching equilibrium simply requires agent values $V^{m}, V^{f}$ and proposal propensities $P^{m}, P^{f}$ to be consistent.

Definition (Matching equilibrium [NTU]). Equilibrium is the set of functions $\left\{P^{m}, P^{f}, V^{m}, V^{f}\right\}$ over $\left(\underline{x}_{m}, \underline{x}_{f}\right) \in\left(\Omega_{m} \times \Omega_{f}\right)$ that satisfy the functional equations (1) $-(2)$ and (4)-(5).

Existence is established by considering the following fixed-point problem. Let $V_{k}^{m}\left(\underline{x}_{m}\right)=V^{m}\left(\underline{x}_{m}\right)$ for all $\underline{x}_{m} \in \Omega_{m}$ describe the equilibrium male values in which equilibrium implies $V_{k}^{m}\left(\underline{x}_{m}\right) \geq u_{m}\left(\underline{x}_{m}\right) / r$. Equation (1) then implies male proposal propensities 
OOO

$$
P_{k}^{m}\left(\underline{x}_{f} \mid \underline{x}_{m}\right)=1-H\left(r\left[V_{k}^{m}\left(\underline{x}_{m}\right)-U_{m}\left(\underline{x}_{m}, \underline{x}_{f}\right)\right]\right) .
$$

Given male proposal propensities $P_{k}^{m}(\cdot) \in[0,1]$, the Bellman equation (5) then uniquely yields $V^{f}\left(\underline{x}_{f}\right)$ for each $\underline{x}_{f} \in \Omega_{f}$. Let $V_{k}^{f}(\cdot)$ denote this solution. Given $V^{f}=V_{k}^{f}(\cdot)$, equation (2) then yields female proposal propensities

$$
P_{k}^{f}(\cdot)=1-H\left(r\left[V_{k}^{f}\left(\underline{x}_{f}\right)-U_{f}\left(\underline{x}_{f}, \underline{x}_{m}\right)\right]\right) .
$$

Of course given these female proposal propensities $P_{k}^{f}(\cdot) \in[0,1]$, (4) then uniquely determines $V^{m}\left(\underline{x}_{m}\right)$ for all $\underline{x}_{m} \in \Omega_{m}$ (and implies $V^{m}\left(\underline{x}_{m}\right) \geq$ $\left.u_{m}\left(\underline{x}_{m}\right) / r\right)$. Let $V_{k+1}^{m}(\cdot)$ denote this updated solution. This identifies functional equation $V_{k+1}^{m}=T V_{k}^{m}$, where equilibrium corresponds to its fixed point $V^{m}=T V^{m}$. The existence proof uses the following monotonicity property.

Lemma 3 (Monotonicity). If $V_{k}^{m}\left(\underline{x}_{m}\right) \geq V_{k+1}^{m}\left(\underline{x}_{m}\right)$ for all $\underline{x}_{m} \in \Omega_{m}$, then $T V_{k}^{m}\left(\underline{x}_{m}\right) \geq T V_{k+1}^{m}\left(\underline{x}_{m}\right)$ for all $\underline{x}_{m} \in \Omega_{m}$.

Proof. As $H(\cdot)$ is an increasing function, $V_{k}^{m}\left(\underline{x}_{m}\right) \geq V_{k+1}^{m}\left(\underline{x}_{m}\right)$ for all $\underline{x}_{m} \in \Omega_{m}$ and (7) implies $P_{k}^{m}(\cdot) \leq P_{k+1}^{m}(\cdot)$ for all $\underline{x}_{m} \in \Omega_{m}, \underline{x}_{f} \in \Omega_{f}$. Lemma 1 establishes $V_{k}^{f}(\cdot) \leq V_{k+1}^{f}(\cdot)$ for all $\underline{x}_{f} \in \Omega_{f}$. As $H(\cdot)$ is an increasing function, $V_{k}^{f}(\cdot) \leq V_{k+1}^{f}(\cdot)$ for all $\underline{x}_{f} \in \Omega_{f}$ and $(8)$ implies $P_{k}^{f}(\cdot) \geq P_{k+1}^{f}(\cdot)$ for all $\underline{x}_{f} \in \Omega_{f}$, $\underline{x}_{m} \in \Omega_{m}$. Lemma 1 establishes $T V_{k}^{m}\left(\underline{x}_{m}\right) \geq T V_{k+1}^{m}\left(\underline{x}_{m}\right)$ for all $\underline{x}_{m} \in \Omega_{m}$, and so the map $T$ is monotonic. QED

The proof of lemma 3 reflects the following structure. When all single men are better off, each man becomes more selective in the marriage market: given a contact with a single woman, each man proposes with a lower probability. Lemma 1 then implies that every single woman is worse off for it is harder to find a man who is willing to form a permanent partnership. Now when all single women are worse off, each becomes less selective in the marriage market and her proposal propensities increase. Lemma 1 then implies that every single man is better off. These feedback effects suggest that multiple equilibria may occur where men, say, prefer an equilibrium in which women are less selective (and men more selective) while women prefer a different equilibrium in which men are less selective (and women more selective). The proof of lemma 3, however, shows that this feedback mechanism also implies monotonicity of the map $T V^{m}$. Establishing existence of an equilibrium is now straightforward.

Theorem 1. A matching equilibrium exists.

Proof. Existence follows by repeated iteration of the map $V_{k+1}^{m}\left(\underline{x}_{m}\right)=$ $T V_{k}^{m}\left(\underline{x}_{m}\right)$, starting at the upper bound $V_{0}^{m}(\cdot)=\bar{V}^{m}(\cdot)$. As $V_{1}^{m}\left(\underline{x}_{m}\right)=$ $T V_{0}^{m}\left(\underline{x}_{m}\right) \leq \bar{V}^{m}\left(\underline{x}_{m}\right)$ for all $\underline{x}_{m} \in \Omega_{m}$, lemma 3 and an induction argument imply a sequence of decreasing values $V_{k+1}^{m}\left(\underline{x}_{m}\right) \leq V_{k}^{m}\left(\underline{x}_{m}\right)$ for each $\underline{x}_{m} \in$ $\Omega_{m}, k=0,1,2, \ldots$. As this sequence is bounded below by $u_{m}\left(\underline{x}_{m}\right) / r$, a limit point exists for every $\underline{x}_{m} \in \Omega_{m}$. As this limiting set of values is the 
required fixed point, an equilibrium must exist. This completes the proof of the theorem. QED

The proof of theorem 1 identifies a simple algorithm by which we can numerically compute matching equilibria. Indeed there are clear parallels with the original algorithm by Gale and Shapley (1962). That algorithm identifies stable match allocations by describing how women make acceptance decisions given the current set of male proposals, and the algorithm sequentially updates the set of male proposal choices given those acceptance rules. Here instead with search frictions, matching equilibria are identified by sequentially updating agent values, which then determine proposal strategies. An added parallel is that if there are two equilibria in which, say, all men prefer equilibrium 1 to equilibrium 2, then monotonicity of the map $T$ implies iteration starting with $V_{0}^{m}(\cdot)=\bar{V}^{m}$ (i.e., men extract full marital surplus in the first step) will converge to equilibrium 1 , while iteration starting with $V_{0}^{m}(\cdot)=u_{m}(\cdot) / r$ (i.e., women extract full marital surplus in the first step) will converge to equilibrium 2.

In the next section we describe a particular application of this framework. Before doing that, however, we show how to extend the argument to the collective household case.

\section{B. Matching Equilibrium with Collective Households}

Consider instead a household $\left(\underline{x}_{m}, \underline{x}_{f}, \underline{\theta}\right)$ with $\underline{\theta}=\left(\theta^{m}, \theta^{f}\right) \in \Theta$, which takes collective actions $\underline{z} \in Z\left(\underline{x}_{m}, \underline{x}_{f}, \underline{\theta}\right)$. Because frictions imply that marital surplus may be strictly positive, an equilibrium framework must describe how that surplus is shared. We adopt the standard Nash bargaining approach: partners $\left(\underline{x}_{m}, \underline{x}_{f}, \underline{\theta}\right)$ choose actions $\underline{z}$ to solve

$$
\max _{\underline{z} \in Z}\left[U^{1}\left(\underline{z}_{x_{m}}, \underline{x}_{f}, \underline{\theta}\right)-V^{m}\right]^{\alpha}\left[U^{2}\left(\underline{z}_{\underline{x}_{m}}, \underline{x}_{f}, \underline{\theta}\right)-V^{f}\right]^{1-\alpha},
$$

where $U^{1}$ and $U^{2}$ are the respective male and female payoffs within the match. Threat points $\left(V^{m}, V^{f}\right)$ are the agents' respective values of remaining single, where $\alpha=1$ implies that the male appropriates all of the match surplus while $\alpha=0$ implies that the female appropriates all the match surplus. Thus $\alpha \in[0,1]$ parameterizes the male share of any match surplus.

As is well known, an equivalent representation is to define the "utility production possibility frontier"; that is, given any household $\left(\underline{x}_{m}, \underline{x}_{f}, \underline{\theta}\right)$, define Pareto frontier $U^{m}=\Upsilon\left(U^{f} \underline{x}_{m}, \underline{x}_{f}, \underline{\theta}\right)$, where

$$
U^{m}=\max _{\underline{z} \in Z} U^{1}\left(\underline{z}_{\underline{x}} \underline{x}_{m}, \underline{x}_{f}, \underline{\theta}\right) \text { subject to } U^{2}\left(\underline{z}_{\mid} \underline{x}_{m}, \underline{x}_{f}, \underline{\theta}\right) \geq U^{f} .
$$

Thus $\Upsilon(\cdot)$ describes the male's maximized marital payoff $U^{m}$ should his partner obtain $U^{f}$. If the Pareto frontier $\Upsilon\left(\cdot \underline{x}_{m}, \underline{x}_{f}, \underline{\theta}\right)$ is not concave (e.g., there may be indivisibilities in the action set $Z$ ), lotteries are then 
optimal (e.g., partners take turns taking out the trash), in which case we consider the convex hull of $\Upsilon\left(\cdot \underline{x}_{m}, \underline{x}_{f}, \underline{\theta}\right)$, which is concave. ${ }^{8}$ Thus whenever a gain to trade exists, marital payoffs $\left(\tilde{U}^{m}, \tilde{U}^{f}\right)$ solve

$$
\begin{aligned}
\left(\tilde{U}^{m}, \tilde{U}^{f}\right) & =\arg \max _{\left(U^{m}, U^{f}\right)}\left[U^{m}-V^{m}\right]^{\alpha}\left[U^{f}-V^{f}\right]^{1-\alpha} \\
\text { subject to } U^{m} & =\Upsilon\left(U^{f} \mid \underline{x}_{m}, \underline{x}_{f}, \underline{\theta}\right) .
\end{aligned}
$$

As in the previous case, women always have the option to remain single, and so their value of being single $V_{f}\left(\underline{x}_{f}\right)$ is no lower than $u^{f}\left(\underline{x}_{f}\right) / r$. Thus in any household in which a gain to trade exists, $\Upsilon\left(u^{f}\left(\underline{x}_{f}\right) / r \mid \underline{x}_{m}\right.$, $\left.\underline{x}_{f}, \underline{\theta}\right)$ describes the maximal male payoff. We ensure that male values exist by assuming

$$
E_{\theta} \Upsilon\left(\frac{u^{f}\left(\underline{x}_{f}\right)}{r} \mid \cdot\right) \quad \text { exists for all }\left(\underline{x}_{m}, \underline{x}_{f}\right) \in\left(\Omega_{m} \times \Omega_{f}\right) .
$$

Because men must have $V_{m}\left(\underline{x}_{m}\right) \geq u^{m}\left(\underline{x}_{m}\right) / r$, (11) ensures that the expected male match surplus is finite for every contact $\left(\underline{x}_{m}, \underline{x}_{f}\right)$. Because match surplus is shared in fixed proportions then, when $\alpha<1$, (11) also ensures that female values exist. ${ }^{9}$

Although concavity ensures that $\Upsilon(\cdot)$ is piecewise differentiable in $U^{f}$, for ease of exposition we assume that it is continuously differentiable. In that case (10) implies that female marital payoff $\tilde{U}^{f}=\tilde{U}^{f}\left(\underline{x}_{m}, \underline{x}_{f}, \underline{\theta}, V^{m}, V^{f}\right)$ is given by the first-order condition

$$
\alpha \Upsilon^{\prime}\left(\tilde{U}^{f} \mid \cdot\right)\left[\tilde{U}^{f}-V^{f}\right]+(1-\alpha)\left[\Upsilon\left(\tilde{U}^{f} \mid \cdot\right)-V^{m}\right]=0
$$

when $\tilde{U}^{f} \geq V^{f}$ (otherwise there is no gain to trade and the match dissolves). Given $\tilde{U}^{f}$, the male negotiates marital payoff $\tilde{U}^{m}\left(\underline{x}_{m}, \underline{x}_{f}, \underline{\theta}, V^{m}, V^{f}\right)$, where

$$
\tilde{U}^{m}=\Upsilon\left(\tilde{U}^{f} \mid \underline{x}_{m}, \underline{x}_{f}, \theta\right) .
$$

We use the same methodology as in the NTU case. The first step is to describe how marital payoffs $\left(\tilde{U}^{m}, \tilde{U}^{f}\right)$ vary with values $\left(V^{m}, V^{f}\right)$.

Lemma 4. Should a gain to trade exist, that is, $\tilde{U}^{m}>V^{m}$, then

i. $0 \leq \partial \tilde{U}^{m} / \partial V^{m} \leq 1$ : the male partner negotiates a higher marital payoff should his threat point increase;

ii. $\partial \widetilde{U}^{m} / \partial V^{f} \leq 0$ : the male partner negotiates a lower marital payoff should his partner's threat point $V^{f}$ increase.

The equivalent statement applies for $\tilde{U}^{f}$.

\footnotetext{
${ }^{8}$ The transferable utility case as defined in the stable matching literature presumes $\Upsilon\left(\cdot \underline{x}_{m}, \underline{x}_{f}, \underline{\theta}\right)$ is linear in $U^{f}$; see, e.g., Chiappori and Weiss (2007) with marital public goods (children).

${ }^{9}$ When instead $\alpha=1$, we must redefine the Pareto frontier as $U^{f}=\Upsilon\left(U^{m} \mid \underline{x}_{m}, \underline{x}_{f}, \underline{\theta}\right)$ and assume $E_{\theta} \Upsilon\left(u^{m}\left(\underline{x}_{m}\right) / r \mid \cdot\right)$ exists. The following ignores this simple caveat.
} 
Proof. The proof requires a trivial comparative static exercise on (12) and (13), noting that $\Upsilon\left(\tilde{U}^{f} \mid \underline{x}_{m}, \underline{x}_{f}, \theta\right)$ is concave in $\tilde{U}^{f}$. QED

We now determine equilibrium values $\left(V^{m}, V^{f}\right)$. Consider a single male $\underline{x}_{m} \in \Omega_{m}$ with value $V^{m}$. If he contacts woman $\underline{x}_{f}$ with equilibrium value $V^{f}=V^{f}\left(\underline{x}_{f}\right)$, then, should a gain to trade exist, he negotiates marital payoff $\tilde{U}^{m}\left(\underline{x}_{m}, \underline{x}_{f}, \underline{\theta}, V^{m}, V^{f}\left(\underline{x}_{f}\right)\right) \geq V^{m}$ as determined by (12)-(13). Conversely, if there is no gain to trade, the two separate and continue search. Standard arguments imply that $V^{m}$ solves the Bellman equation:

$$
\begin{aligned}
r V^{m}= & u_{m}\left(\underline{x}_{m}\right)+\lambda \int_{\underline{x}_{f} \in \Omega_{f}} E_{\theta}\left\{\operatorname { m a x } \left[\tilde{U}^{m}\left(\underline{x}_{m}, \underline{x}_{f}, \underline{\theta}, V^{m}, V^{f}\left(\underline{x}_{f}\right)\right)\right.\right. \\
& \left.\left.-V_{m}, 0\right]\right\} d G_{f}\left(\underline{x}_{f}\right) .
\end{aligned}
$$

Expression (14) is an implicit function for $V^{m}=V^{m}\left(\underline{x}_{m}\right)$ given the distribution $G_{f}$ of female singles and their values $V^{f}(\cdot)$, where equilibrium $V^{f}\left(\underline{x}_{f}\right) \geq u_{f}\left(\underline{x}_{f}\right) / r$ for all $\underline{x}_{f} \in \Omega_{f}$. The right-hand side of (14) is greater than $u_{m}\left(\underline{x}_{m}\right) \geq 0$, and lemma 4 (i) implies that it is a continuous, decreasing function of $V^{m}$. Now consider $V^{m}=u_{m}\left(\underline{x}_{m}\right) / r$ and note that lemma 4(ii) and $V^{f}\left(\underline{x}_{f}\right) \geq u_{f}\left(\underline{x}_{f}\right) / r$ imply

$$
\begin{gathered}
E_{\theta} \max \left\{\tilde{U}^{m}\left[\underline{x}_{m}, \underline{x}_{f}, \underline{\theta}, \frac{u_{m}\left(\underline{x}_{m}\right)}{r}, V^{f}\left(\underline{x}_{f}\right)\right]-\frac{u_{m}\left(\underline{x}_{m}\right)}{r}, 0\right\} \\
\leq E_{\theta} \max \left\{\Upsilon\left[\frac{u_{f}\left(\underline{x}_{f}\right)}{r} \mid \cdot\right], \frac{u_{m}\left(\underline{x}_{m}\right)}{r}\right\}-\frac{u_{m}\left(\underline{x}_{m}\right)}{r}
\end{gathered}
$$

and (11) ensures that this upper bound exists. Hence for $V^{m} \geq u_{m}\left(\underline{x}_{m}\right) / r$, the right-hand side of (14) is a finite, continuous, decreasing function that is bounded below by $u_{m}\left(\underline{x}_{m}\right)$. It now follows that a solution to (14) exists, is unique, and implies $V^{m}\left(\underline{x}_{m}\right) \geq u_{m}\left(\underline{x}_{m}\right) / r$.

By symmetry, $V^{f}=V^{f}\left(\underline{x}_{f}\right)$ solves the Bellman equation

$$
\begin{aligned}
r V^{f}= & u_{f}\left(\underline{x}_{f}\right)+\lambda \int_{\underline{x}_{m} \in \Omega_{m}} E_{\theta} \max \left[\tilde{U}^{f}\left(\underline{x}_{m}, \underline{x}_{f}, \theta \mid V^{m}\left(\underline{x}_{m}\right), V^{f}\right)\right. \\
& \left.-V^{f}, 0\right] d G_{m}\left(\underline{x}_{m}\right) .
\end{aligned}
$$

Given distribution $G_{m}$ of male single types and male values $V^{m}(\cdot)$ satisfying $V^{m}\left(\underline{x}_{m}\right) \geq u_{m}\left(\underline{x}_{m}\right) / r$ for all $\underline{x}_{m} \in \Omega_{m}$, the same argument establishes that a solution to (15) exists, is unique, and implies $V^{f}\left(\underline{x}_{f}\right) \geq u_{f}\left(\underline{x}_{f}\right) / r$.

A matching equilibrium for the collective household case simply requires that negotiated marital payoffs $\left(\tilde{U}^{m}, \tilde{U}^{f}\right)$ and values $\left(V^{m}, V^{f}\right)$ are consistent.

Definition (Matching equilibrium for collective households). Equilibrium is the set of functions $\left\{\tilde{U}^{m}, \tilde{U}^{f}, V^{m}, V^{f}\right\}$ over $\left(\underline{x}_{m}, \underline{x}_{f}\right) \in\left(\Omega_{m} \times \Omega_{f}\right)$ and $\underline{\theta} \in \Theta$, which satisfy the functional equations (12)-(15). 
Because the same fixed-point argument as in Section II.A applies, we sketch the relevant details. Let $V_{k}^{m}\left(\underline{x}_{m}\right)=V^{m}\left(\underline{x}_{m}\right)$ for all $\underline{x}_{m} \in \Omega_{m}$ describe the equilibrium male values, where equilibrium implies $V_{k}^{m}\left(\underline{x}_{m}\right) \geq$ $u_{m}\left(\underline{x}_{m}\right) / r$. With $V^{m}=V_{k}^{m}(\cdot)$, (10) and (15) jointly determine $V^{f}\left(\underline{x}_{f}\right)$ for each $\underline{x}_{f} \in \Omega_{f}$, and the above has established that a solution for $V^{f}\left(\underline{x}_{f}\right)$ exists, is unique, and implies $V^{f}\left(\underline{x}_{f}\right) \geq u_{f}\left(\underline{x}_{f}\right) / r$. Let $V_{k}^{f}$ denote this solution. With $V^{f}=V_{k}^{f}(\cdot),(10)$ and (14) now determine $V^{m}\left(\underline{x}_{m}\right)$ for each $\underline{x}_{m} \in \Omega_{m}$, and the above has established that a solution for $V^{m}\left(\underline{x}_{m}\right)$ exists, is unique, and implies $V^{m}\left(\underline{x}_{m}\right) \geq u_{m}\left(\underline{x}_{m}\right) / r$. Let $V_{k+1}^{m}$ denote these updated male values, and note we have established $V_{k+1}^{m}\left(\underline{x}_{m}\right) \geq u_{m}\left(\underline{x}_{m}\right) / r$. A fixed point of the functional equation $V_{k+1}^{m}=T V_{k}^{m}$ describes the matching equilibrium.

We again establish monotonicity. Consider male values $V_{k}^{m}$ and $V_{k+1}^{m}$ with the property that $V_{k}^{m}\left(\underline{x}_{m}\right) \geq V_{k+1}^{m}\left(\underline{x}_{m}\right) \geq u_{m}\left(\underline{x}_{m}\right) / r$ for all $\underline{x}_{m} \in \Omega_{m}$. Consider any female $\underline{x}_{f} \in \Omega_{f}$, and note that lemma 4(ii) implies $\partial \tilde{U}^{f} / \partial V^{m} \leq 0$; that is, a female negotiates a lower payoff the greater the male threat point. It is immediate that if all men have higher threat points $V_{k}^{m} \geq$ $V_{k+1}^{m}$, the lower female marital payoff $\tilde{U}^{f}$ in every match implies that her $V^{f}$ must be lower; that is, $V_{k}^{f}\left(\underline{x}_{f}\right) \leq V_{k+1}^{f}\left(\underline{x}_{f}\right)$ for all $\underline{x}_{f} \in \Omega_{f}$. By symmetry, it follows that if all women have lower threat points $V_{k}^{f} \leq V_{k+1}^{f}$, then each male negotiates a higher payoff $\tilde{U}^{m}$ in any match. Thus $T V_{k}^{m}\left(\underline{x}_{m}\right) \geq$ $T V_{k+1}^{m}\left(\underline{x}_{m}\right)$ for all $\underline{x}_{m} \in \Omega_{m}$ and $T$ is monotonic.

Finally, we identify an upper bound on male values: define $\bar{V}^{m}\left(\underline{x}_{m}\right)$ as the solution to (14) when $V^{f}\left(\underline{x}_{f}\right)=u_{f}\left(\underline{x}_{f}\right) / r$ for all $\underline{x}_{f} \in \Omega_{f}$, that is, when women have minimal threat points. The above implies that a solution for $\bar{V}^{m}$ exists and is unique and $\bar{V}^{m}\left(\underline{x}_{m}\right) \geq u\left(\underline{x}_{m}\right) / r$ for all $\underline{x}_{m} \in \Omega_{m}$.

Existence now follows by repeated iteration of the functional equation $V_{k+1}^{m}=T V_{k}^{m}$ starting at $V_{0}^{m}=\bar{V}^{m}$. Monotonicity and an induction argument imply a decreasing sequence of values $V_{k}^{m}\left(\underline{x}_{m}\right)$ for $k=0,1,2, \ldots$, and, as every $V_{k}^{m}\left(\underline{x}_{m}\right)$ is bounded below by $u_{m}\left(\underline{x}_{m}\right) / r$, a limit point must exist. Because this set of limiting values is a fixed point of the functional equation $V_{m}=T V_{m}$, a matching equilibrium exists.

Multiple equilibria are again possible. One can instead begin the iteration at minimal male values, that is, set $V_{0}^{m}\left(\underline{x}_{m}\right)=u\left(\underline{x}_{m}\right) / r$ for each $\underline{x}_{m} \in \Omega_{m}$. Iteration of the functional equation then yields an increasing sequence of values $V_{k}^{m}\left(\underline{x}_{m}\right)$ for $k=0,1,2, \ldots$ that are bounded above by $\bar{V}^{m}\left(\underline{x}_{m}\right)$.

\section{Other Bargaining Protocols}

Following Binmore (1987), the bargaining literature has considered how the assumptions of the dynamic bargaining game may, or may not, map into a particular axiomatic Nash bargaining solution. This literature raises the issue of whether divorce is a credible threat should a partner fail a household task. An alternative approach instead assumes that threat points 
depend on inside options, that is, that neither partner might cooperate on household tasks (Lundberg and Pollak 1993). If $\underline{z}^{\text {Nash }}$ describes household actions taken in the event of noncooperation, one might instead adopt the Nash bargaining solution

$$
\max _{\underline{z} \in Z}\left[U^{1}(\underline{z} \mid \cdot)-U^{1}\left(\underline{z}^{\text {Nash }} \mid \cdot\right)\right]^{\alpha}\left[U^{2}(\underline{z} \mid \cdot)-U^{2}\left(\underline{z}^{\text {Nash }} \mid \cdot\right)\right]^{1-\alpha}
$$

to determine the terms of trade. The outside option principle then implies that if $V^{f}>U^{2}\left(\underline{z}^{\text {Nash }} \mid \cdot\right)$, so that divorce by the female partner is indeed credible, the relevant threat points revert to $\left(V^{m}, V^{f}\right)$.

Regardless of the assumed bargaining protocol, however, what is crucial for the existence of the matching equilibrium is the underlying payoff structure: is it the case that if all men have increased values $V^{m}$ this implies that all women have reduced values $V^{f}$ ? Oftentimes this will be true, either because NTU implies that women receive fewer proposals or because bargaining implies that women negotiate reduced marital payoffs. If so, the value map $T$ is then monotonic, and, along with bounded payoffs, this not only is sufficient to imply existence of equilibrium but also identifies a simple algorithm that computes it numerically.

\section{Application: The Impact of Equal Opportunities for Women}

To focus on female outcomes, we keep the male side deliberately simple: each male is characterized by a scalar, $\underline{x}_{m} \equiv y$, which describes his labor market earnings. Earnings across single men have distribution $G^{m}(\cdot)$ and support $[\underline{y}, \bar{y}]$. Each woman instead has two attributes $(\alpha, n)$, where "ability" $\alpha$ describes her earnings capabilities in the labor market while "charm" $n$ describes her innate charm to men, an asset that is assumed to be nonproductive in the labor market but valuable in the marriage market.

We extend the matching framework to include an ex ante investment decision. Prior to entering the marriage market, we suppose that each woman makes an education choice $e \in\{0,1\}$, with $e=1$ indicating university education and $e=0$ otherwise. The cost of university education $c>0$ is the same for all. We assume that a woman $(n, \alpha)$ earns $w=\alpha$ when $e=0$ and $w=\gamma \alpha$ when $e=1$, where $\gamma>1$ describes the wage return to education.

Given sunk education choice $e$, each woman $(n, \alpha)$ is described by her ex post characteristics $(n, w)$. We let $G_{0}^{f}(n, \alpha)$ denote the exogenous distribution of underlying female attributes and $G^{f}(n, w)$ denote the postinvestment distribution of female characteristics.

We adopt the simpler NTU framework. Household consumption is a joint public good and labor supply is jointly efficient with marital payoffs: 


$$
\begin{aligned}
U^{m} & =\frac{\beta[y+\max [w-\phi, 0]]+n}{r}, \\
U^{f} & =\frac{\beta[y+\max [w-\phi, 0]]}{r},
\end{aligned}
$$

where $\beta$ and $\phi$ are positive parameters. The term $y+\max [w-\phi, 0]$ describes joint labor market earnings, where $\phi$ denotes the opportunity cost of child care; that is, the female partner continues in the labor market if her earnings $w \geq \phi$. Thus married women with $w<\phi$ become homemakers and do not participate in the labor market. ${ }^{10}$ Joint earnings are deflated by $\beta \in(0,1]$, a parameter we discuss in greater detail in the conclusion. The male flow payoff to a match thus depends on (deflated) joint earnings $\beta[y+\max [w-\phi, 0]]$ and partner charm $n$. We refer to $z(n, w)=$ $\beta \max [w-\phi, 0]+n$ as female "fitness" and note that male payoffs take the form $U^{m}(y, z)$. The female match payoff $U^{f}$ depends on deflated joint earnings but does not depend directly on her own charm. That is not to say that charm has no value to her, for it directly affects male proposals when single. We assume flow payoffs $u^{m}(y)=y, u^{f}(n, w)=w$ while single; that is, flow utility equals flow income.

An investment equilibrium requires female education choice to be privately optimal. Unfortunately, the investment problem is not necessarily well behaved because education increases fitness $z=z(n, w)$, which, in turn, affects male proposal propensities. The following numerical example identifies an investment equilibrium in which, for every charm $n$, there exists an ability threshold $\alpha_{n}$ such that women $(\alpha, n)$ invest if and only if ability $\alpha \geq \alpha_{n}$. The assumed thresholds $\left\{\alpha_{n}\right\}$ determine the ex post type distributions $\left\{G^{m}, G^{f}(n, w) \mid \alpha_{n}\right\}$, and the matching equilibrium then determines values $\left\{V^{m}, V^{f} \mid \alpha_{n}\right\}$. Identifying an investment equilibrium requires solving numerically for $\left\{\alpha_{n}\right\}$ such that $V^{f}\left(n, \gamma \alpha_{n}\right)-V^{f}\left(n, \alpha_{n}\right)=c$ for all $n$. Because the return to education is not necessarily increasing with ability, we have to verify numerically that women $\alpha>\alpha_{n}$ do indeed prefer $e=1$, while women $\alpha<\alpha_{n}$ prefer $e=0$.

\section{A. Numerical Example}

Table 1 describes the functional forms and parameter values used (see the appendix for motivation). This numerical example presumes just two levels of female charm: that type $i=\mathcal{H}$ women have charm $n_{\mathcal{H}}=\bar{n} / 2$ and type $i=\mathcal{L}$ women have $n_{\mathcal{L}}=-\bar{n} / 2$. Figure 3 graphs (annuitized) female values

${ }^{10}$ An alternative specification assumes that the lower earner assumes child care responsibilities (e.g., Coles and Francesconi 2011). 
TABLE 1

Baseline Parameters and Functional Forms

\begin{tabular}{ll}
\hline \hline Parameter & \multicolumn{1}{c}{ A. } \\
\hline$r$ & .04 (per year) $^{c}$ \\
$\phi$ & $\$ 10,732$ (per year) \\
& Truncated lognormal, with $\mu_{m}=\$ 10.440$ and \\
$G^{m}(y)$ & $\sigma_{m}=\$ 0.687^{\mathrm{b}}$ \\
{$[y, \bar{y}]$} & {$[9,608,157,192]\left(\$\right.$ per year) ${ }^{\mathrm{b}}$} \\
$\bar{G}^{f}(\alpha \mid n)$ & $G^{m}(\cdot)$ rescaled by $\gamma$ \\
$G^{f}(n \mid \alpha)$ & Symmetric binomial, with draws from $\{-\bar{n} / 2, \bar{n} / 2\}$ \\
$H(\cdot)$ & $H$ is normally distributed with mean $=F$ and $\mathrm{SD}=\sigma$ \\
$c$ & $\$ 57,069$ (over 4 years) $^{\mathrm{c}}$ \\
\hline & \multicolumn{1}{c}{ B. } \\
\hline$\lambda$ & $7.86^{\mathrm{d}}$ \\
$\beta$ & .51 \\
$F$ & $\$ 31,000^{\mathrm{d}}$ \\
$\sigma$ & $\$ 8,300^{\mathrm{d}}$ \\
$\bar{n}$ & $\$ 51,800$ (per year) \\
$\gamma$ & 1.047 \\
\hline
\end{tabular}

Note.-The parameter values shown in panel B are obtained by calibration. See Coles and Francesconi (2017).

a Source: Macartney and Laughlin (2011).

b Values are from the 2000 US census.

c The values are computed using information on average annual cost for undergraduate tuition and fees in public institutions from the National Center for Education Statistics, US Department of Education, Digest of Education Statistics: 2013 (http://inces.ed.gov); information on the Federal Minimum Wage in 2000 is from the US Department of Labor, History of Federal Minimum Wage Rates under the Fair Labor Standards Act, 1938-2009 (http:// www.dol.gov/whd/minwage/chart.htm); and information on earnings of female high school graduates us from the 2000 US census.

d Estimates are yearly values.

$$
v_{i}(\alpha) \equiv r \max \left[V^{f}\left(n_{i}, \alpha\right), V^{f}\left(n_{i}, \gamma \alpha\right)-c\right]
$$

by ability $\alpha$ and charm type $i=\mathcal{L}, \mathcal{H}$ in an investment equilibrium.

The stable matching literature with transferable utility would imply that each woman extracts 100 percent of the value of her charm $n$ to men (for men bid competitively for partners). But in a search framework with NTU, a more charming woman can extract value only by being suitably selective over male partners. Figure 3 demonstrates that the female return to charm $v_{H}(\alpha)-v_{L}(\alpha)$ falls steeply with ability. For example, single women $\underline{\alpha}$ obtain a female return to charm of 88 percent, that is, $v_{H}(\underline{\alpha})-v_{L}(\underline{\alpha})=$ $0.88 \bar{n}$, while the highest-ability types have a return equal to just 15 percent. This occurs because high-earning single women are already highly selective in the singles market and, for them with NTU, added female charm (which further increases male proposal rates) provides relatively little added value. The converse is the case for low-ability women on low earn- 
$\mathrm{OOO}$

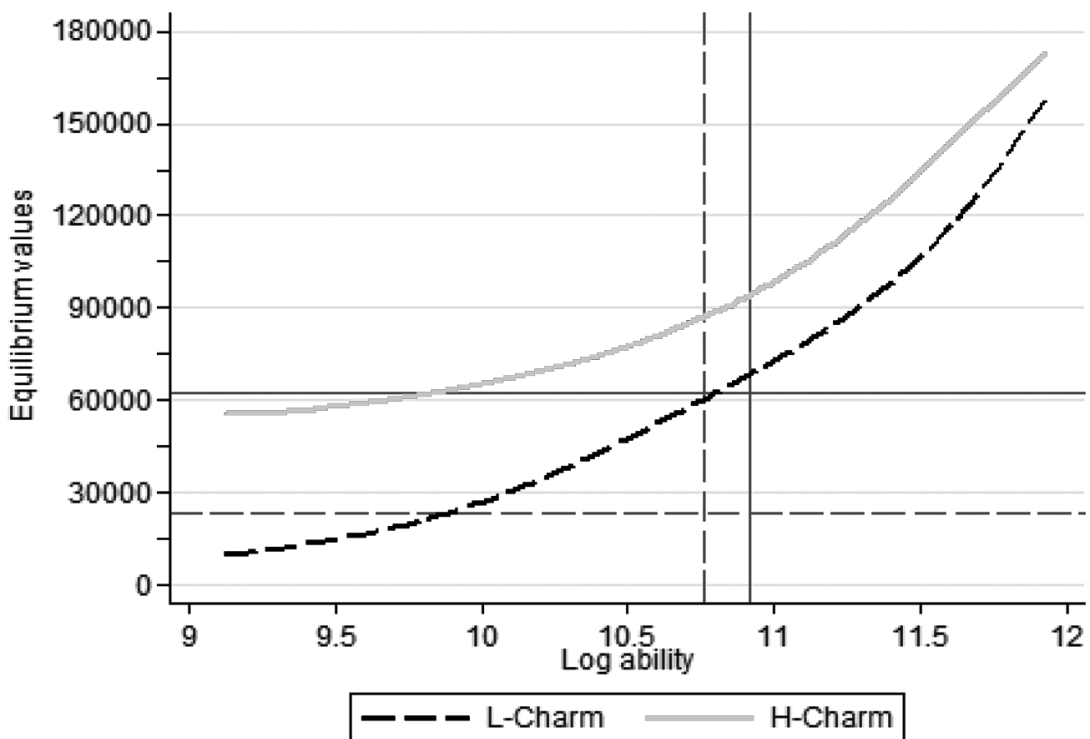

FIG. 3.-Equilibrium values by charm type, with unequal and equal opportunities. All dashed figures refer to type $\mathcal{L}$ women, while all continuous figures refer to type $\mathcal{H}$ women. The two horizontal lines refer to the equilibrium flow values without equal opportunities by charm type. The two upward-sloping curves refer to the equilibrium flow values with equal opportunities, that is, $v_{\mathcal{L}}(\alpha)$ and $v_{\mathcal{H}}(\alpha)$. The two vertical lines identify the investment thresholds by charm type, that is, $\alpha_{\mathcal{L}}$ and $\alpha_{\mathcal{H}}$. Color version available as an online enhancement.

ings: for them added charm is much more valuable in trying to attract desirable male partners.

The investment equilibrium finds that type $\mathcal{L}$ women have the greater incentive to invest in education (for them education has the larger impact on male proposal propensities). The vertical lines in figure 3 describe the ability thresholds $\alpha_{\mathcal{L}}, \alpha_{\mathcal{H}}$, where women with ability to the right of these thresholds invest in education.

\section{B. The Impact of Equal Opportunities}

To illustrate the impact of equal opportunities on female outcomes and values, we adopt a polar view of the "marriage bar": that is, prior to the 1964 Civil Rights Act, mothers could earn only low wages $\underline{y}$ in the labor market. Because the numerical example specifies child care costs $\phi>\underline{y}$, marital preferences (16) imply that married women leave the labor market to raise the family and payoffs simplify to

$$
U^{m}=\frac{\beta y+n}{r} \text { and } U^{f}=\frac{\beta y}{r} .
$$

The marriage bar not only severely reduces the labor market participation rates of mothers but also yields very different matching incentives: 
payoffs (17) imply that single males value potential partners solely by charm. Assuming for simplicity that single women also earn only low wages $\underline{y}$, an investment equilibrium then finds that women do not invest in a college education. Solving numerically for a matching equilibrium is straightforward and yields annuitized values $v_{\mathcal{H}}, v_{\mathcal{L}}$, which are independent of ability and correspond to the horizontal lines as drawn in figure 3 .

Not surprisingly, high-ability women are much better off with equal opportunities. But lower-ability women are worse off: equal opportunities in the labor market for them yield little added value while equilibrium in the marriage market moves against them: the increase in fitness across higher-ability women makes men more selective. Equal opportunities also have a large, differential impact on the female return to charm: with equal opportunities charm becomes more valuable to low-ability women and less valuable to high-ability women, where unequal opportunities instead yield a return of 76 percent.

\section{Conclusion}

This paper has developed an equilibrium marriage model of two-sided search in which ex ante heterogeneous individuals have general payoff functions with vectors of attributes. The approach is powerful for it identifies a simple algorithm that, in the numerical application, is found to rapidly converge to equilibrium. The numerical example extends the framework to include an endogenous investment margin and is used to demonstrate how the arrival of equal opportunities had far-reaching consequences for women, in both the labor and marriage markets. Given the straightforward extension to the collective household case, many future extensions and applications are possible.

An important insight for future research is the central role played by parameter $\beta$ (in the numerical example) in explaining female hazard rates into partnership formation. To understand its role, note for a married couple with two children that the 2008 OECD income equivalence scale is 2.1. Thus given family joint earnings $w+y$, the OECD equivalent scale implies that individual consumption within the family is deflated to $\beta(w+y)$, where $\beta=0.48$ (where $0.48=1 / 2.1$ ).${ }^{11}$ Consider then a single woman with wage $w>\phi$ who receives a proposal. The search framework implies that she compares (i) the value of continued search, which depends on her flow consumption $w$ while single plus the option value of seeking a preferred partner, to (ii) being married and here raising a family with two children, which yields deflated flow utility $\beta w$ plus added flow utility $\beta(y-\phi)+\theta^{f}$ proffered by the male proposer.

${ }^{11}$ Guvenen and Rendall (2015) use income equivalence scales to model the costs of divorce and show how female college education may provide insurance against future divorce risk. 
An obvious case is $\beta=1$, which implies that marrying an equal-earning partner doubles consumption, net of fixed $\operatorname{cost} \beta \phi$. But because equilibrium sorting generates positive assortive matching, $\beta=1$ is problematic for it implies that high-earning women then have a keener incentive to match more quickly. In essence $1-\beta$ describes a "family tax" on own earnings, where a large value of $1-\beta$ is central to explaining why highearning single women match relatively slowly (Coles and Francesconi 2017). Greater charm, interestingly, has the opposite effect. When a more charming female can monetize the value of her charm only by partnership, she has a greater incentive to match more quickly. By changing the relative values of female ability and charm, the arrival of equal opportunities and the family tax fundamentally affect the timing of partnership, the degree of positive assortative matching across partners, and family earnings inequality.

Although the focus of the paper has been on the marriage market, it also applies to equilibrium matching in the labor market with wage bargaining. Of course, steady-state equilibrium in a labor market framework requires solving for not only the matching equilibrium, as done here, but also the steady-state distribution of types that depends on the inflows and outflows of trading agents. This generates additional sorting externalities, for agent entry and match strategies then affect the steady-state composition of singles, and feedback effects may generate multiple equilibria (Burdett and Coles 1999). In numerical work, updating the type distribution by solving standard steady-state flow conditions is not a difficult computational problem (Greenwood et al. [2016], among others). Such composition effects also arise in a marriage market context when fertility is an endogenous choice. For example, Baudin, de la Croix, and Gobbi (2015) find that more educated women are more likely to remain childless.

\section{Appendix}

\section{A. Data Sources}

Our data sources, which we use for the discussion in the introduction and the numerical exercise in Section III, come from the Integrated Public Use Microdata Series (IPUMS) of the decennial censuses (Ruggles et al. 2010).

We use decennial censuses from 1850 to 2000 (1890 is missing) and the 2009 American Community Survey (ACS) sample, which is a 1 percent national random sample of the population. Detailed information on education, which is grouped in 12 different categories in the variable EDUC, is not available before the 1940 census. Data on labor force participation come from the variable LABFORCE and cover all census years with the exception of 1850, in which the information for women is not recorded. For our analysis we select only women who are aged between 25 and 34 for the education and labor market statistics. 
The sample size therefore varies across censuses and outcomes. Sample sizes for figures 1 and 2 therefore vary from about 20,000 women in 1860 to about 1 million in 2000 .

Figure 1 shows the trends in the proportion of women aged 25-34 who are in paid employment, expressed in percentage terms. Unemployed women and women who are out of the labor force in that age range are in the base category. Besides all women, the figure also shows the trends for mothers and for women who are single and never married. ${ }^{12}$ Figure 2 shows the proportion of women aged 25-34 who have a university degree or higher qualification.

Finally, data on male earnings come from the 2000 census and are computed using the variable INCWAGE. The statistics reported in the text (table 1) are calculated on all males born between 1951 and 1960 (hence aged 40-49 in 2000) after dropping the top and bottom 1 percent of the distribution of INCWAGE out of the analysis.

\section{B. A Note on the Parametric Assumptions Used in the Application}

The parameters reported in the top panel of table 1 are chosen as follows. All women are assumed to have a standard annual discount rate of $r=4$ percent. Child care costs, $\phi$, are set at $\$ 10,732$ per year for two children. This figure comes from the estimate of child care expenditures of 19.9 percent of female yearly personal income per child by Macartney and Laughlin (2011, table 2). With an average personal labor income of $\$ 26,964$ from the 2000 census $(\$ 21,750$ for the 75 percent low-education women and $\$ 41,350$ for the 25 percent college-educated women), this estimate leads to annual child care costs of $\$ 5,366$ per child (or $\$ 10,732$ for two children, as assumed in the model).

The distribution of male earnings $G_{m}(y)$ is (truncated) lognormal. The 2000 census data on male earnings yield a mean of 10.44 and a standard deviation of 0.687 . We truncate at two standard deviations from the mean, so that $\underline{y}=\$ 9,608$ and $\bar{y}=\$ 157,192$ per year, and renormalize the probability weights accordingly. The distribution $G_{f}(\alpha)$ is also a truncated lognormal distribution, where we assume that women have the same distribution of abilities as men, but deflated by parameter $\gamma>1$. Thus if all women invest in education, equal opportunities imply that women enjoy the same distribution of wages.

The cost of education, $c$, is computed as follows. The source is the National Center for Education Statistics, US Department of Education (http://inces.ed.gov), Digest of Education Statistics: 2013. According to this source, the average annual cost for undergraduate tuition and fees in public institutions offering a 4-year degree calculated between 2000 and 2003 is $\$ 3,967.25$ in current dollars (with values ranging from $\$ 3,501$ to $\$ 4,587$ ). The corresponding total over the 4 -year period is $\$ 15,869$. (The same annual statistic including room and board is $\$ 9,575$ for a total over the 4-year period of $\$ 38,300$.) Our measure of opportunity cost is based on the Federal Minimum Wage in 2000 of $\$ 5.15$ per hour (source: US Department of Labor, History of Federal Minimum Wage Rates under the Fair Labor

\footnotetext{
12 Because data on marital status are available only since the 1880 census and not before, the employment series for single, never-married women can be constructed only from that year onward.
} 
Standards Act, 1938-2009, http://www.dol.gov/whd/minwage/chart.htm). Assuming 2,000 hours per year for a full-time worker ( 40 weekly hours over 50 weeks in a year), total annual earning will be $\$ 10,300$, which over 4 years becomes $\$ 41,200$. Summing up this and the direct cost of education leads to a total of $\$ 57,069$ over 4 years. An alternative measure of the opportunity cost is given by the observed average earnings for women of all races, who are high school graduates (including GED) and are aged 18-21. This figure is $\$ 9,042$ (standard deviation $=\$ 11,076$ ) from the 2000 US census. Over the 4-year period, this translates to $\$ 36,168$, which summed up to the direct cost of education becomes $\$ 52,037$. We have performed the analysis using this new estimate, but all our results remain unchanged. Finally, we have also performed the analysis using the figure for the cost of education that includes room and board. This is $\$ 79,500$ over the 4 -year period. Again, all the results of the paper are qualitatively unchanged.

The distribution of female charm is assumed to be orthogonal to the distribution of female abilities. Although Hamermesh and Biddle (1994) find evidence of a positive impact of workers' physical looks on their earnings, we simplify by abstracting from this effect. As there is no objective information on the distribution of charm $n$ in the population (Buss 2003), we suppose there are just two levels $n \in\{-\bar{n} / 2, \bar{n} / 2\}$, which is symmetrically distributed, and so $\bar{n}$ also describes the standard deviation of charm across single women.

The distribution of idiosyncratic (match-specific) draws, $H(\cdot)$, is assumed to be $N\left(F, \sigma^{2}\right)$, where $F$ describes the expected net increase in flow utility through starting a family.

Coles and Francesconi (2017) identify the remaining parameter values by calibrating the model to the correlation of partner incomes prior to match formation, female education rates, and on empirical hazard functions, which describe the rate at which women enter first partnership by education choice and age. Because the family tax $1-\beta$ is large, the imputed return to raising a family, $F=$ $\$ 31,000$ per year, is large to compensate. The estimated return to education, $\gamma=4.7$ percent, yields the target female education rate of 25.5 percent. This latter estimate is very close to the average returns to education found in all the twins studies reviewed by Card (1999). Notice that it is also in line with the estimates reported in discrete choice dynamic programming models, such as Eckstein and Wolpin (1989).

\section{References}

Acemoglu, Daron, David H. Autor, and David Lyle. 2004. "Women, War, and Wages: The Effect of Female Labor Supply on the Wage Structure at Midcentury." J.P.E. 112 (3): 497-551.

Albanesi, Stefania, and Claudia Olivetti. 2016. "Gender Roles and Medical Progress." J.P.E. 124 (3): 650-95.

Baudin, Thomas, David de la Croix, and Paula E. Gobbi. 2015. "Fertility and Childlessness in the United States." A.E.R. 105 (6): 1852-82.

Becker, Gary S. 1973. "A Theory of Marriage: Part I.” J.P.E. 81 (4): 813-46. . 1974. "A Theory of Marriage: Part II." J.P.E. 82 (2, pt. 2): S11-S26.

Beller, Andrea H. 1982. "The Impact of Equal Opportunity Policy on Sex Differentials in Earnings and Occupations." A.E.R. Papers and Proc. 72 (2): 171-75. 
Belot, Michèle, and Marco Francesconi. 2013. "Dating Preferences and Meeting Opportunities in Mate Choice Decisions." J. Human Resources 48 (2): 474-508.

Binmore, Ken G. 1987. "Perfect Equilibria in Bargaining Models." In The Economics of Bargaining, edited by Ken G. Binmore and Partha Dasgupta, 77-105. Oxford: Blackwell.

Bloch, Francis, and Harl Ryder. 2000. "Two-Sided Search, Marriages, and Matchmakers." Internat. Econ. Rev. 41 (1): 93-115.

Browning, Martin, and Pierre-André Chiappori. 1998. "Efficient Intra-household Allocations: A General Characterization and Empirical Tests." Econometrica 66 (6): 1241-78.

Browning, Martin, Pierre-André Chiappori, and Yoram Weiss. 2014. Economics of the Family. Cambridge: Cambridge Univ. Press.

Burdett, Kenneth, and Melvyn G. Coles. 1997. "Marriage and Class." Q.J.E. 112 (1): 141-68.

— 1999. "Long-Term Partnership Formation: Marriage and Employment." Econ. J. 109:F307-F334.

. 2001. "Transplants and Implants: The Economics of Self-Improvement." Internat. Econ. Rev. 42 (3): 597-616.

Burdett, Kenneth, and Randall Wright. 1998. "Two-Sided Search with Nontransferable Utility." Rev. Econ. Dynamics 1 (1): 220-45.

Buss, David M. 2003. The Evolution of Desire: Strategies of Human Mating. Rev. ed. New York: Basic Books.

Card, David. 1999. "The Causal Effect of Education on Earnings." In Handbook of Labor Economics, vol. 3, edited by Orley Ashenfelter and David Card, chap. 30. Amsterdam: Elsevier.

Chade, Hector. 2001. "Two-Sided Search and Perfect Segregation with Fixed Search Costs." Math. Soc. Sci. 42 (1): 31-51.

Chade, Hector, and Gustavo Ventura 2002. "Taxes and Marriage: A Two-Sided Search Analysis." Internat. Econ. Rev. 43 (3): 955-85.

Chiappori, Pierre-André. 1992. "Collective Labor Supply and Welfare." J.P.E. 100 (3): 437-67.

Chiappori, Pierre-André, Sonia Oreffice, and Climent Quintana-Domeque. 2012. "Fatter Attraction: Anthropometric and Socioeconomic Matching on the Marriage Market." J.P.E. 120 (4): 659-95.

Chiappori, Pierre-André, and Yoram Weiss. 2007. "Divorce, Remarriage, and Child Support." J. Labor Econ. 25 (1): 37-74.

Choo, Eugene, and Aloysius Siow. 2006. "Who Marries Whom and Why." J.P.E. 114 (1): 175-201.

Cole, Harold L., George J. Mailath, and Andrew Postlewaite. 1992. "Social Norms, Savings Behavior, and Growth." J.P.E. 100 (6): 1092-1125.

Coles, Melvyn G., and Marco Francesconi. 2011. "On the Emergence of Toyboys: The Timing of Marriage with Aging and Uncertain Careers." Internat. Econ. Rev. 52 (3): 825-53.

- 2017. "Equilibrium Search and the Impact of Equal Opportunities for Women.” Discussion Paper no. 12095 (June), Centre Econ. Policy Res., London.

Costa, Dora L. 2000. "From Mill Town to Board Room: The Rise of Women's Paid Labor.” J. Econ. Perspectives 14 (4): 101-22.

Díaz-Giménez, Javier, and Eugenio Giolito. 2013. "Accounting for the Timing of First Marriages." Internat. Econ. Rev. 54 (1): 135-58.

Doepke, Matthias, Moshe Hazan, and Yishay D. Maoz. 2015. "The Baby Boom and World War II: A Macroeconomic Analysis.” Rev. Econ. Studies 82 (3): 1031-73. 
Dupuy, Arnaud, and Alfred Galichon. 2014. "Personality Traits and the Marriage Market." J.P.E. 122 (6): 1271-1319.

Eckstein, Zvi, and Kenneth I. Wolpin. 1989. "Dynamic Labour Force Participation of Married Women and Endogenous Work Experience." Rev. Econ. Studies 56 (3): 375-90.

Eeckhout, Jan. 1999. "Bilateral Search and Vertical Heterogeneity." Internat. Econ. Rev. 40 (4): 869-87.

Fernandez, Raquel, Alessandra Fogli, and Claudia Olivetti. 2004. "Mothers and Sons: Preference Formation and Female Labor Force Dynamics." Q.J.E. 119 (4): 1249-99.

Fisman, Raymond, Sheena S. Iyengar, Emir Kamenica, and Itamar Simonson. 2006. "Gender Differences in Mate Selection: Evidence from a Speed Dating Experiment.” Q.J.E. 121 (2): 673-97.

Gale, David, and Lloyd S. Shapley. 1962. "College Admissions and the Stability of Marriage." American Math. Monthly 69 (1): 9-15.

Galichon, Alfred, Scott Duke Kominers, and Simon Weber. 2019. "Costly Concessions: An Empirical Framework for Matching with Imperfectly Transferable Utility." J.P.E., forthcoming.

Galichon, Alfred, and Bernard Salanié. 2010. "Matching with Trade-Offs: Revealed Preferences over Competing Characteristics." Manuscript, Soc. Sci. Res. Network. http://dx.doi.org/10.2139/ssrn.1487307.

Gautier, Pieter A., Michael Svarer, and Coen N. Teulings. 2010. "Marriage and the City: Search Frictions and Sorting of Singles." J. Urban Econ. 67 (2): 206-18.

Goldin, Claudia. 1990. Understanding the Gender Gap: An Economic History of American Women. New York: Oxford Univ. Press.

— 1991. "Marriage Bars: Discrimination against Married Women Workers from the 1920s to the 1950s." In Favorites of Fortune: Technology, Growth, and Economic Development since the Industrial Revolution, edited by Patrice Higonnet, David S. Landes, and Henry Rosovsky, 511-36. Cambridge, MA: Harvard Univ. Press.

2006. "The Quiet Revolution That Transformed Women's Employment, Education, and Family." A.E.R. Papers and Proc. 96 (2): 1-21.

Goldin, Claudia, and Lawrence F. Katz. 2002. "The Power of the Pill: Oral Contraceptives and Women's Career and Marriage Decisions." J.P.E. 110 (4): 730-70.

Goldin, Claudia, and Claudia Olivetti. 2013. "Shocking Labor Supply: A Reassessment of the Role of World War II on Women's Labor Supply." A.E.R. Papers and Proc. 103 (3): 257-62.

Goussé, Marion, Nicolas Jacquemet, and Jean-Marc Robin. 2017. "Marriage, Labor Supply, and Home Production." Econometrica 85 (6): 1873-1919.

Greenwood, Jeremy, Nezih Guner, Georgi Kocharkov, and Cezar Santos. 2016. "Technology and the Changing Family: A Unified Model of Marriage, Divorce, Educational Attainment, and Married Female Labor-Force Participation.” American Econ. J.: Macroeconomics 8 (1): 1-41.

Greenwood, Jeremy, Ananth Seshadri, and Guillaume Vandenbroucke. 2005. "The Baby Boom and Baby Bust." A.E.R. 95 (1): 183-207.

Greenwood, Jeremy, Ananth Seshadri, and Mehmet Yorukoglu. 2005. "Engines of Liberation." Rev. Econ. Studies 72 (1): 109-33.

Guvenen, Fatih, and Michelle Rendall. 2015. "Women's Emancipation through Education: A Macroeconomic Analysis." Rev. Econ. Dynamics 18 (4): 931-56.

Hamermesh, Daniel S., and Jeff E. Biddle. 1994. "Beauty and the Labor Market." A.E.R. 84 (5): 1174-94. 
Harrison, Cynthia E. 1988. On Account of Sex: The Politics of Women's Issues, 19451968. Berkeley: Univ. California Press.

Hitsch, Günther J., Ali Hortaçsu, and Dan Ariely. 2010. "Matching and Sorting in Online Dating." A.E.R. 100 (1): 130-63.

Hsieh, Chang-Tai, Erik Hurst, Charles I. Jones, and Peter J. Klenow. 2018. "The Allocation of Talent and U.S. Economic Growth." Manuscript, Booth School, Univ. Chicago. https://faculty.chicagobooth.edu/chang-tai.hsieh/research /HHJK.pdf.

Kessler-Harris, Alice. 1982. Out to Work: A History of Wage-Earning Women in the United States. New York: Oxford Univ. Press.

- 2001. In Pursuit of Equity: Women, Men, and the Quest for Economic Citizenship in 20th Century America. New York: Oxford Univ. Press.

Lindenlaub, Ilse, and Fabien Postel-Vinay. 2017. "Multidimensional Sorting under Random Search.” Manuscript. https://sites.google.com/site/ilselindenlaub $/$ research/Lindenlaub_PostelVinay.pdf?attredirects $=0 \& d=1$.

Lu, Xiaohua, and R. Preston McAfee. 1996. "Matching and Expectations in a Market with Heterogeneous Agents." In Advances in Applied Microeconomics, vol. 6, edited by Michael R. Baye, 121-56. Greenwich, CT: JAI.

Lundberg, Shelly, and Robert A. Pollak. 1993. "Separate Spheres Bargaining and the Marriage Market.” J.P.E. 101 (6): 988-1010.

Macartney, Suzanne, and Lynda Laughlin. 2011. "Child Care Costs in the Current Population Survey's Annual Social and Economic Supplement (CPS ASEC): A Comparison to SIPP." Working Paper no. 2011-1, Social, Economic, and Housing Statistics Division, US Census Bur., Washington, DC.

Rosen, Ruth. 2000. The World Split Open: How the Modern Women's Movement Changed America. New York: Viking.

Ruggles, Steven, J. Trent Alexander, Katie Genadek, Ronald Goeken, Matthew B. Schroeder, and Matthew Sobek. 2010. Integrated Public Use Microdata Series: Version 5.0. Minneapolis: Univ. Minnesota.

Shimer, Robert, and Lones Smith. 2000. "Assortative Matching and Search." Econometrica 68 (2): 343-69.

Smith, Lones. 2006. "The Marriage Model with Search Frictions." J.P.E. 114 (6): $1124-44$.

Stone, Lawrence. 1977. The Family, Sex and Marriage in England, 1500-1800. New York: Harper \& Row. 